\title{
MARKETING, ESTRATÉGIA E IDENTIDADE DE EMPRESA ("MERCATOR" E "STRATEGOR")
}

1. Jacques Lendrevie, Denis Lindon, Pedro Dionísio e Vicente Rodrigues, $M E R$ CATOR: Teoria e prática do marketing, col. «Gestão \& Inovação», série «Ciências de Gestão», 1, 2.a ed., Lisboa, Publ. Dom Quixote, 1992, 516+XLVIII p.

2. Jean-Pierre Anastassopoulos et al., Estratégia. Estrutura. Decisão. Identidade. STRATEGOR: Política global de empresa (trad. do francês), col. «Gestão \& Inovação», série «Ciências de Gestão», 2, Lisboa, Publ. Dom Quixote, 1993, $441 \mathrm{p}$.

O significativo desenvolvimento, registado pelas ciências económicas e de gestão nas últimas décadas, tem induzido a publicação de uma vasta literatura, sobre as respectivas temáticas. A própria realidade "Empresa" começou a ser valorizada como objecto de estudo ${ }^{1}$, recuperando assim, finalmente, o lugar destacado que lhe compete na história contemporânea, ao lado de organizações, tradicional e historicamente mais prestigiadas e estudadas, como a Escola, a Igreja, a Instituição Militar e a Família. Deste modo, não surpreende que, em alguns países - França, Grã-Bretanha, Itália e Estados Unidos da América, entre outros -, se multipliquem as revistas e os livros especializados e, bem assim, que certas editoras como, em França, «Les Éditions d'Organisation» - se dediquem à publicação de títulos acerca das aludidas temáticas, a um ritmo impressionante.

$\mathrm{O}$ referido movimento, ainda que com algum atraso e lentidão - de acordo com o habitual, num país semi-periférico como Portugal —, vai chegando até nós, o que é demonstrado por determinadas iniciativas editoriais - como aquelas de que resultou a divulgação, pelas Publicações Dom Quixote, das obras referenciadas em epígrafe -, as quais merecem ser sublinhadas como bastante positivas. Para simplificar, mencioná-las-ei, de forma abreviada, por Mercator e Strategor, respectivamente.

1. A obra MERCATOR: Teoria e prática do marketing consta de um prefácio, uma introdução, quatro partes - com um total de dezassete capítulos -, uma 
conclusão, bibliografia e índices, além de cerca de meia centena de páginas com «Histórias de sucesso em marketing», relativas a outras tantas organizações portuguesas.

$\mathrm{Na}$ introdução esclarece-se a temática geral —, isto é, o marketing —, nas suas diversas componentes: características, funções, definição e tendências actuais. De entre estas, destacam-se: por um lado, a definição generalizada proposta, segundo a qual «O marketing é o conjunto dos métodos e dos meios de que uma organização dispõe para promover, nos públicos pelos quais se interessa, os comportamentos favoráveis à realização dos seus próprios objectivos» (p. 25); por outro, a extensão do marketing a novos sectores de actividade, já que, além dos tradicionais bens de consumo e semiduráveis, aquele "invadiu" também domínios de bens e serviços de índole política, turística, cultural, educativa, etc. (p. 24-25).

Do que se acaba de expor, pode tirar-se a seguinte ilação: o marketing não interessa, apenas, a quem produz ou vende bens ou mesmo aos gestores, em geral, mas sim a todos os indivíduos de uma sociedade. É que todos eles, numa ou outra ocasião, por um ou outro motivo, se encontrarão em determinadas situações - como produtores, vendedores ou consumidores, prestadores ou utentes de serviços, agentes ou público-alvo de campanhas de opinião - , nas quais o marketing actua, de forma mais ou menos evidente.

Na primeira parte procede-se ao «estudo de mercado», sob as seguintes perspectivas: descrição, comportamento dos consumidores, segmentação e métodos de previsão. Entre outras possíveis, dão-se duas definições de "mercado". Numa (sentido restrito), coloca-se a tónica nos «dados quantitativos sobre a importância, a estrutura e a evolução das vendas de um produto». $\mathrm{Na}$ outra (sentido lato), privilegia-se o público, definindo-se mercado como «o conjunto dos "públicos" susceptíveis de exercer uma influência nas vendas de um produto» (p. 40). Na «representação esquemática de um mercado» (p. 44, fig. 1.1.), acrescentam-se diversas outras componentes do mercado. Contudo, devia ter-se prestado mais atenção às coordenadas espaço-tempo, condicionadas pelas distâncias e pelo sistema de comunicações. Trata-se de um assunto também relacionado com a segmentação (geográfica) do mercado, subjacente à própria adjectivação do conceito "mercado" (local, regional, nacional ou internacional).

Ao analisar-se o comportamento dos consumidores (cap. 2, p. 81-119), estudam-se, fundamentalmente, as necessidades e as motivações. Tratando-se de uma problemática bastante complexa e com diversas vertentes, analisam-se os vários tipos de necessidades humanas (segundo a conhecida teoria de A. Maslow) e, bem assim, os factores de ordem psicológica e sociocultural. Sob este ponto de vista, é de salientar a seguinte observação: «Os indivíduos não diferem somente através da classe social mas também através da cultura. É este o nome dado ao conjunto de valores, normas e comportamentos que caracterizam uma sociedade» (p. 108). 
Como é sabido, relaciona-se com este factor a crescente importância que a cultura de empresa tem vindo a assumir, assunto a que, oportunamente, voltarei.

$\mathrm{Na}$ segunda parte focam-se as «variáveis do marketing», desde as políticas de preço, de produto e de comunicação, à distribuição, aos instrumentos de venda, à publicidade $\mathrm{e}$ às relações públicas.

Como pedra de toque de várias passagens, sublinha-se a tendência para uma certa "humanização" do marketing, ao deslocar-se, do produto para as pessoas, o alvo principal daquele. Essa nova filosofia da empresa, introduzida pelo marketing - ou seja, o "estado de espírito marketing", na expressão dos autores (p. 168) —, está bem patente nas seguintes expressões: a) «Produtos são, como tudo o resto, gente e o drama que lhe está associado». b) «O presidente da SAS, a companhia aérea sueca, afirmou que a "SAS fazia voar os seus aviões, agora faz voar os seus clientes"» (p. 168).

A "estratégia de marketing» é abordada na terceira parte, a qual abrange os capítulos dedicados à estratégia de marketing e política geral da empresa, a formulação de objectivos, as grandes opções estratégicas e a formulação e avaliação do marketing-mix.

Dada a importância da imagem em qualquer estratégia de marketing — para já não falar da própria civilização em que estamos inseridos, em que a imagem desempenha papel fulcral - especifica-se o que deve entender-se por aquela. Assim, a propósito do conceito de "posicionamento", acrescenta-se: «A imagem de um produto, junto de um determinado mercado, é o conjunto das características objectivas ou simbólicas que lhe são atribuídas por esse mercado. Por outras palavras, é o conjunto dos conhecimentos, crenças e evocações que são associados por um determinado público, a um produto» (p. 417). No fundo - poder-se-ia acrescentar -, aquilo que pretendemos exprimir quando, sobre um determinado produto/serviço, nos referimos simplesmente a imagem de marca, para fazer realçar a sua boa qualidade.

Por seu turno, na quarta e última parte, estudam-se o planeamento, o controlo e a organização dos serviços de marketing. Uma das ideias a reter é assim expressa por Alberto Meirelles, num dos prefácios ao cap. 17: «Esta visão marca a nova etapa do Marketing para os anos 90: o Marketing total, que relaciona a empresa não só com os consumidores mas com todos os seus parceiros: clientes, fornecedores e obviamente os seus colaboradores» (p. 470; sublinhado meu). Quer dizer, além do marketing praticado extramuros - geralmente mais comum -, há que não descurar o que deve ser levado a cabo intramuros, inclusive como reforço da imagem (da organização/produto), já anteriormente referida.

«As tendências e as perspectivas actuais do marketing» são analisadas na conclusão. Sem pretender ser exaustivo, permito-me salientar os seguintes aspectos. Em primeiro lugar, o profissionalismo e o rigor com que o marketing deve ser encarado, uma vez que ele «é, e tenderá cada vez mais a ser, uma ciência» 
(p. 487). Em segundo lugar, o "núcleo duro" do marketing encontra-se no indivíduo ou grupo humano a que se dirige, pelo que se afirma expressamente: «Uma empresa com orientação de MARKETING na verdade não vende Produtos - conquista Clientes» (p. 487). Consequentemente, a ética deve estar presente - ou, pelo menos, subjacente - nas estratégias desenvolvidas no âmbito do marketing. A propósito, escreveu Hortência Barandas: «A ética nos negócios não se limita à teoria racional e individual do bem e do mal, de acordo com a tradição filośfica e religiosa ocidental, mas traduz-se antes pelo exercício da responsabilidade no que respeita à assunção do risco, à prática da justiça, à eficácia das decisões, à criatividade, etc.» (p. 490). Finalmente, uma outra tendência, patente em algumas empresas, refere-se à progressiva passagem de um marketing de massas (ou indiferenciado) para um marketing segmentado, o qual, na sua forma extrema, pode chegar mesmo a um marketing individualizado. Também aqui se evidencia a valorização hierárquica do cliente, em relação ao produto.

Referenciado, de forma bastante sucinta, o conteúdo de Mercator, resta aludir expressamente à colaboração protuguesa, a qual muito contribui para valorizar e enriquecer a dita obra. A mencionada colaboração verificou-se a três níveis: a) nos múltiplos prefácios aos diversos capítulos, por especialistas das respectivas matérias, em geral com sólida preparação teórico-prática; b) nas «Dez Histórias de sucesso em marketing», com o contributo de gestores/quadros ligados às respectivas organizações; c) na própria co-autoria da obra, através dos autores portugueses - Pedro Dionísio e Vicente Rodrigues -, inclusive na adaptação à realidade portuguesa e na própria indicação de vários exemplos pertinentes, oriundos do nosso tecido empresarial.

Sem desejar, como é óbvio, diminuir a importância e o significado da obra Mercator - agora acessível, em português -, permito-me, contudo, fazer alguns pequenos reparos ou sugestões, a fim de, eventualmente, poderem vir a ser contemplados em posteriores edições.

As «Histórias de sucesso em marketing», ainda que resumidas ${ }^{2}$, revestem-se da maior importância, não só por se tratar de organizações "vencedoras" e líderes nas respectivas áreas - e, consequentemente, susceptíveis de fornecer imagens positivas -, como pela esclarecedora ilustração de que são acompanhadas. Todavia, a sua localização no interior do texto (entre as p. 240 e 241 ), com paginação independente e sem que na capa, frontispício e índice se lhes faça qualquer alusão (a qual só aparece na primeira badana e no prefácio geral), não permite dar-lhes o realce que, em meu entender, merecem. Elas poderiam, por exemplo, constituir uma quinta parte da obra, com paginação seguida e indicação expressa na capa, no frontispício e no índice (aqui com especificação dos dez casos). Também a profusão de gráficos e quadros, elucidativos e geralmente bem elaborados, 122 deviam constar de um índice, no final, complementando assim os existentes. 
À cultura de empresa é dedicada pouca atenção, pois só esporadicamente é referida. Além disso, a própria valorização do património histórico, arquivístico e tecnológico, através da museologia - inclusive no âmbito da Associação Portuguesa de Empresas com Museu (APOREM) -, merecia que se lhe fizesse algumas referências, no que se refere ao marketing cultural.

Por último, das gralhas/lapsos detectados, anoto somente os casos mais flagrantes, indicando entre [...] a forma correcta:

- «Organizações com [sem] fins lucrativos» (p. 24);

- «conceito de mercado [marketing]» (p. 37);

- «indivíduos do segundo [primeiro] e terceiro tipo» (p. 93);

- «tratavam-se [tratava-se] dos lares» (p. 137);

- «fazer crer nos [aos] consumidores» (p. 248);

- «existência de polos [pólos]» (p. 270);

- três linhas [de "O director-geral" a "aquela máquina"] encontram-se repetidas;

- «adaptado [adaptada] de Russol Ackof» (p. 393);

- «adeqúem [adequem]» (p. 408);

- «mercado alvo [mercado-alvo]» (p. 426);

- «melhor [mais bem]» (p. 250, 267 e 306).

Antes de concluir, apenas gostaria de frisar, novamente, que se trata de uma obra importantíssima, actualizada e bastante completa, na qual teoria e prática se entrecruzam de forma harmoniosa e equilibrada. Da sua leitura muito podem beneficiar, além de um público mais vasto, alunos, investigadores e professores de gestão e de economia, gestores (de recursos humanos, financeiros ou mesmo de organizações culturais, políticas religiosas, de assistência, etc.), profissionais das áreas do marketing e das relações públicas, agentes de desenvolvimento, dinamizadores culturais, operadores e guias turísticos. A forma didáctica como está organizado - com esquemas, gráficos, quadros, alíneas e subalíneas - permite que Mercator, além de livro de consulta e/ou de leitura despreocupada, funcione igualmente como um bom manual da respectiva matéria. O próprio êxito editorial — duas edições em 1992 e a terceira em preparação - também confirma, de algum modo, as considerações aqui efectuadas.

2. Por sua vez, em STRATEGOR: Política global de empresa, analisam-se as seguintes quatro vertentes: Estratégia, Estrutura, Decisão e Identidade. Além destas - cada uma focada em sua parte, ao longo de dezanove capítulos -, a obra inicia-se com um prefácio e uma introdução geral e termina com uma conclusão e um glossário, bibliografia e índices. 
$\mathrm{Na}$ introdução geral os autores começam por caracterizar a política de empresa, como «uma das mais jovens ciências do "management"». E acrescentam: «O seu objecto é a empresa enquanto actor da vida económica e social. Visa conhecer as determinantes, endógenas e exógenas, deste actor, a fim de explicar os seus comportamentos passados, prever e, sobretudo, orientar os seus comportamentos futuros. As suas finalidades fazem dela, deste modo, a disciplina mais directamente ligada à direcção geral da empresa, a mais útil ao exercício do cargo de dirigente» (p. 17). Como pilares da política de empresa, indicam as já mencionadas estratégia, estrutura, decisão e identidade (p. 20).

A estratégia, focada na primeira parte, é estudada de acordo com os seguintes parâmetros: concorrência, custos, especialização e diferenciação, tecnologia e aspectos relacionais. Ao estudarem os meios para medir a posição concorrencial da empresa, os autores indicam as seguintes categorias de critérios (p. 53):

- a posição no mercado;

- a posição da empresa em matéria de custos;

- a imagem e a implantação comercial;

- as competências técnicas e a perícia tecnológica;

- a rendibilidade e o poder financeiro.

No que toca à especialização $v s$. diversificação, sublinha-se o contraste entre os anos sessenta e setenta - "anos loucos" da diversificação - e a actualidade, em que se nota tendência inversa: «A crise que a economia mundial conhece desde 1974 encarregou-se de corrigir e de racionalizar essa "corrida". A palavra de ordem hoje em dia é, antes, a de cada um se recentrar na respectiva actividade de base» (p. 121).

Estratégia e tecnologia é o tema abordado no capítulo oitavo. Da tecnologia, isto é, da «aplicação concreta de conhecimentos científicos e técnicos à concepção, ao desenvolvimento e ao fabrico de um produto» depende, em muitos casos, o sucesso ou o fracasso das empresas (p. 139). Como um dos exemplos de sucesso, menciona-se um produtor de vidro plano, sediado em St. Helens (Região de Liverpool, na Grã-Bretanha), sobre o qual se pode ler (p. 141): «A invenção do processo conhecido por "float glass" pelo grupo Pilkington proporcionou-lhe uma tal vantagem de custos sobre os concorrentes, que a maior parte destes se viram obrigados a adquirir este processo - e portanto a pagarem voltosas importâncias - para continuarem a ser competitivos» ${ }^{3}$.

Salientando as limitações dos modelos da concorrência - apesar de serem estes os mais usados -, os autores estudam também as «estratégias relacionais» (cap. 9). Sobre o assunto, esclarecem: «Uma estratégia diz-se relacional quando se baseia não na lei da concorrência, mas em relações privilegiadas que a empresa estabelece com certos parceiros do seu contexto» (p. 157). A propósito, permita- 
-se-me que abra aqui um parêntesis: muitas das nossas Pequenas e Médias Empresas (PMEs), no quadro comunitário e de crescente internacionalização da economia, poderão tirar mais benefícios da referida estratégia relacional que de uma estratégia abertamente concorrencial, dado a desequilíbrio de recursos entre os contendores em presença.

Na segunda parte é abordada a estrutura. Como se sabe, esta consiste numa rede de relações de determinados elementos, devidamente integrados num todo. Para os autores de Strategor, «estrutura é o conjunto das funções e das relações que determinam formalmente as missões que cada unidade da organização deve executar, e os modos de colaboração dessa unidade» (p. 185).

Como determinantes da estrutura têm-se apontado factores exógenos (a dimensão da empresa, a sua tecnologia e o contexto) e variáveis internas, como os jogos de poder entre indivíduos e a própria cultura. Acerca desta, os autores acrescentam: «a influência da cultura nacional sobre o comportamento dos indivíduos no seio das organizações foi posta em evidência, de modo retumbante, pelos sucessos japoneses» (p. 190). Notam ainda que, «de um país para outro, se observam diferenças culturais cujo impacto sobre a estrutura das empresas é considerável» (p. 205).

A decisão é objecto de estudo na terceira parte. São focados, entre outros, os seguintes subtemas: planeamento de empresa, modos fundamentais de processos de decisão e modelos de decisão estratégica. Esta é determinada por três grupos de factores (p. 319):

- «a cultura e a "herança" histórica da empresa;

- o contexto, que exerce sobre a empresa um número maior ou menor de pressões, mais ou menos intensas, num horizonte temporal mais ou menos próximo e variável;

- a estrutura da organização e o estilo de management».

A última parte (quarta) é dedicada à identidade ou, se se preferir, à cultura de empresa, embora os autores prefiram a primeira designação (p. 351). Mas, o que deve entender-se por identidade? $\mathrm{Na}$ introdução ao assunto esclarece-se: «A organização é composta de seres humanos, que têm uma certa presença, e a acção colectiva numa dada empresa é geralmente marcada por uma lógica coerente, que a distingue de qualquer outra. Esta lógica constitui-se e afirma-se no tempo. Dá à empresa uma certa continuidade; permite às pessoas identificar essa firma e, em certos casos, identificar-se com ela. É o que se chama identidade». Em seguida, os autores salientam: «Os anos oitenta terão sido marcados pela redescoberta desta dimensão humana» (p. 349). Uma das componentes mais fortes da cultura de empresa é, precisamente, a identidade. Daí o relevo que lhe é dado nessa parte de Strategor e, inclusive, Wally Olins lhe ter dedicado toda uma obra, aliás notável ${ }^{4}$. 
Todavia, como já referi, os autores introduzem algumas distinções entre os dois conceitos, ao sublinharem: «O termo identidade é mais pertinente que o de cultura, embora este seja muito usado na literatura. Cultura é um termo mais passivo - quando o que está em causa é procurar as vias da liberdade de agir - e também mais asséptico, logo mais manipulado». E continuam: «Cultura fica ao nível do superficial, das ideias de valores ou de crenças, e do que se convencionou chamar o universo simbólico (as ideologias, mitos, rituais, tabus e as normas de comportamento que os exprimem). A identidade inscreve-se ao nível das paixões e dos fantasmas. A noção de identidade interroga-se sobre os modos de emergência dessas imagens e desses símbolos; é aqui que se encontra o verdadeiro problema do poder» (p. 251).

Da distinção apresentada - algo discutível, por revelar um conceito de cultura de empresa um tanto reducionista - decorre a interessante perspectiva que apresentam no capítulo 18 , intitulado «A identidade revelada: o contributo da psicologia psicanalítica». Por exemplo, na «abordagem psicanalítica da liderança» (p. 372-376), apresenta-se uma tipologia dos líderes (narcísico, possessivo, sedutor e sábio), a qual se pode revelar funcional, na compreensão dos mecanismos psicológicos e comportamentais, numa estratégia de gestão. Tratar-se-á, pois, de um bom auxiliar, na gestão da própria identidade (cap. 19, p. 381-402).

Como se infere do que fica sumariamente exposto, estamos perante uma obra da maior utilidade para os que se interessem pela gestão e, de modo particular, pelo campo vastíssimo, que é o da política global da empresa. Os fundamentos desta - estratégia, estrutura, decisão e identidade - são estudados com clareza, recorrendo-se a vasta literatura, especializada e actualizada. A orientação bibliográfica (p. 423-433) pode dar uma excelente ajuda a alunos, investigadores, docentes ou profissionais de gestão, que desejem aprofundar certos assuntos.

A despeito do que fica expresso, permito-me fazer algumas observações e reparos. Embora se trate de uma obra de carácter geral e não sobre a realidade portuguesa, dever-se-iam ter acrescentado algumas observações, em nota, sublinhando a nossa especificidade. Atente-se, por exemplo, na seguinte afirmação: «Não é por acaso que numerosas empresas decidiram, nos últimos anos, escrever a sua história» (p. 396). Como é sabido, dado que em Portugal é reduzido o número de empresas em tais condições, a dita afirmação, infelizmente, ainda não se ajusta ao caso português.

Alguns lapsos e/ou gralhas devem ser corrigidos em futuras reedições, pelo que destaco os seguintes, colocando entre [...] as formas correctas:

- faltam as notas 6 (p. 175) e 5 (p. 345);

- «uma abordagem demasiado de marketing» [uma abordagem de marketing demasiado ou de demasiado marketing?]; 
- «savoir faire» [savoir-faire] (p. 126, 132, 147), em contraste com o que vem a p. 170, 173, 209 e 210, onde está certo;

- a legenda da fig. 10.7 (p. 195) devia ter a mesma orientação da própria figura;

- por vezes, os títulos de algumas obras não se encontram em itálico (p. 345 , nota 4 ; p. 403 , cap. 17 , nota 2 );

- «suiça e suiços» [suíça e suíços];

- «constituíu» [constituiu] (p. 356 e 359);

- «tratado com [como] um chefe de Estado» (p. 361);

- «propôr [propor]» (p. 363) e «tentamos [tentámos]» (p. 407).

As observações acabadas de fazer são, essencialmente, de pormenor, pelo que em nada diminuem a importância de uma obra como Strategor, cuja leitura se recomenda vivamente e à qual, por certo, estará reserado um êxito editorial, pelo menos análogo ao do Mercator ( . $^{\circ} 1$ da colecção), anteriormente focado.

José M. Amado Mendes

\section{NOTAS}

1. Giulio Sapelli, L'impresa come soggeto storico, Milão, Il Saggiatore, 1990.

2. Ver outras histórias, do mesmo tipo, em História das Empresas, $10^{\circ}$ vol., Nova Nórdica/Tempo/Promopresse, 1988. Sobre monografias mais desenvolvidas, ver «Histórias privadas contam o passado das empresas mas não chegam ao público», Fortuna, ano 2, n. $^{\circ} 18$, Setembro 1993, "Fortuna/Vintage", p. 21-22.

3. Foi, aliás, o que fez a COVINA, instalada em Santa Iria da Azóia. Para mais informações acerca do dito grupo, ver a sua história, elaborada por T. C. Barker, The Glassmaker. Pilkington: the rise of an international company, 1826-1976, Londres, Weidenfeld and Nicolson, 1977. A preservação e divulgação do património industrial do dito grupo efectua-se, também, através de um excelente museu de empresa ("Pilkington Glass Museum. St. Helens — England"), cuja visita me deixou uma excelente impressão (Maio de 1989), em virtude de aquele se assemelhar mais a um museu nacional do vidro que a um museu de uma organização privada.

4. Trata-se de Wally Olins, Identité d'entreprise. Pour rendre la stratégie d'entreprise visible (trad. do inglês), Paris, Inter Éditions, 1991. 